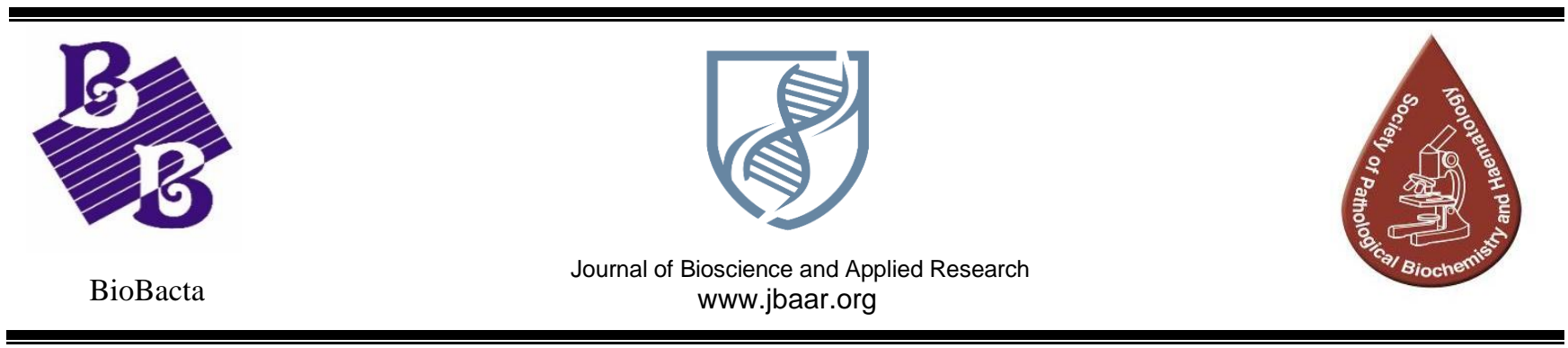

\title{
Genetic variations in some Egyptian Zea mexicana genotypes based on RAPD and AFLP markers
}

\author{
K.H. Radwan ${ }^{1,2 *}$, G.A. Abdelfattah ${ }^{1,3}$, M.A. Badawi ${ }^{1,4}$, E. M. Zayed ${ }^{5}$, M.M. Tarrd ${ }^{6}$. Manal M. S. \\ El-Baghdady ${ }^{1}$, Reem M. Abd El-Maksoud ${ }^{1}$ \\ 1. Agricultural Genetic Engineering Research Institute (AGERI), Agricultural Research Center (ARC), Giza -12619, Egypt. \\ 2. National biotechnology Network of Expertise, ASRT, Egypt. \\ 3. Department of Pharmacology and Toxicology, College of Pharmacy, Prince Sattam Bin Abdulaziz University, Al-Kharj, KSA. \\ 4. Dép. des Sciences Biologiques, Univ. du Québec à Montréal, Montréal, QC H3C 3P8, Canada. \\ 5. Cell Study Research Department (CSRD), Field Crops Research Institute, Agriculture Research Center (ARC), Giza 12619, Egypt. \\ 6. Forage Crops Research Department (FCRD), Field Crops Research Institute, Agriculture Research Center (ARC), Giza-12619, Egypt. \\ * Corresponding author at: Microbial Molecular Biology Department, AGERI, ARC. \\ Giza-12619 Egypt.Tel.0020235727831, e-mail address: khradwan@gmail.com
}

DOI: $10.21608 /$ jbaar.2021.177577

\begin{abstract}
Maize-Teosinte hybrids are of significant interest to maize breeders as a resource of genetic diversity during the maize domestication process as a genetic pool for maize improvement. This study examines the genetic diversity and population structure of 16 Zea mexicana populations which are currently active in Zea breeding programs in Egypt using Random Amplified Polymorphic DNA (RAPD) and Amplified Fragment Length Polymorphism (AFLP) markers. RAPD analysis (14 primers) produced 141 bands; out of which, 102 (72.3\%) were polymorphic. On the other hand, AFLP (5 primer combinations) yielded 276 peaks including 267 (96.7\%) polymorphic ones with an average of 53.4 peaks per primer combination. A total of 11 unique RAPD markers were created by 6 primers and identified 8 genotypes. The five primer combinations generated 56 unique amplicons that successfully distinguished 12 out of the 16 genotypes tested. Furthermore, the number of observed alleles (Na), effective multiplex ratio (EMR), and polymorphic information content (PIC) indices showed higher values for AFLP (2.00, 53.4, and 0.21) than for RAPD (1.67, 7.3, and 0.15). Cluster analysis based on Nei and Li genetic distance and an Unweighted Pair Group Method with Arithmetic Mean (UPGMA) revealed 5 main clusters representing the 16 Zea mexicana confirming the population structure analysis obtained. High variability of the studied teosinte genotypes using RAPD and AFLP markers will provide valuable tools for Zea mexicana breeding programs in Egypt.
\end{abstract}

Keywords: Zea Mexicana, AFLP, RAPD, molecular markers, genetic diversity.

\section{INTRODUCTION}

Both Maize (Zea mays) and teosinte (Zea mexicana) belong to the genus Zea. However, Zea mays ssp. mays are the only cultivated species, while the other species are considered as wild grasses and referred to as teosintes (Sánchez et al., 2011). Maize-Teosinte hybrids have been of considerable interest to both maize and teosinte breeders (Chavez et al., 2012) 
since they can assist in tracking the migration pathways of maize from its origin centers as well as helping in understanding the fate of genetic diversity during the maize domestication process (Varsha et al., 2018). Moreover, teosinte genes have the potential to help improve productivity, disease resistance, flooding tolerance, and nutritional quality (Sánchez et al., 2018; Petr et al., 2018; Kyu et al., 2018 and Tanvir et al., 2018).

Likewise, maize-teosinte or teosinte-maize hybrids have also received attention for enhancing the fodder production potential of teosinte by taking advantage of the hybrid vigor shown by the hybrids. Therefore, Teosinte cultivation was recently utilized as a summer forage crop in Egypt (Radwan et al., 2000; Fukunaga et al., 2005 and Wafaa M. Sharawy et al., 2011). Teosinte has the advantage of giving very high yields, due to profuse tillering capacity that is absent in fodder maize. In addition to the ability to give three cuts against one cut obtained from fodder maize (Sakr, 2017). In addition, maize-teosinte crosses like maize can be safely fed on at any stage of growth (Hassan et al., 2017). Thus, the intelligent use of this valuable genetic resource depends on the understanding of the genetic diversity among and within teosinte populations (Sánchez et al., 2011). Also, understanding phylogenetic relationships could be utilized for understanding maize domestication and evolution, for effective decisions on in situ conservation of teosinte species, and exploiting the potential of teosinte for further genetic enhancement of maize (Prasanna, 2012).

Molecular markers are considered the ideal choice to be used in plant genetic diversity studies because of their unambiguous genetic resource's characterization at the DNA level (Barcaccia et al., 2016). Also, they are stable and detectable in all plant tissues at different developmental stages or under different environmental conditions (Violeta et al., 2018). Because of the simplicity of the random amplified polymorphic DNAs (RAPDs), it has been extensively used to differentiate and detect differences among genotypes (Suten et al., 2013 and Tomkowiak, et al., 2020). RAPD does not require any specific knowledge of the DNA sequence of the target organism. The identical 10-mer primers will or will not amplify a segment of DNA, depending on positions that are complementary to the sequence of the primers (Franklin et al., 1999). On the other hand, although AFLP is more demanding and laborsome, it is a very powerful tool for assessing DNA fingerprinting because of its capacity to reveal a large number of bands in a single amplification, and the resulting higher efficiency index regardless of the plant origin or complexity (Molin et al., 2013 and Mohamed et al., 2016).

The present study was carried out to estimate the level of polymorphism among Sixteen Zea mexicana accessions using two different molecular markers: RAPD and AFLP, to identify unique DNA markers to generate a fingerprint for each genotype that acts as a unique identity for conservation, to assess the genetic relationships and population structure between these genotypes thus helping in choosing the most likely parents from a selection of candidates for future breeding programs in Egypt.

\section{MATERIAL AND METHODS:}

\section{Study Area}

The present investigation was carried out at the Agricultural Genetic Engineering Research Institute (AGERI), Agricultural Research Center (ARC), Giza, Egypt.

\section{plant material}

Sixteen Zea mexicana accessions were provided by Forage Crops Research Department (FCRD), Field Crops Research Institute, Agriculture Research Center (ARC), Giza, Egypt. Zea mexicana genotypes and corresponsive pedigree are listed in Table (1). 
Table 1 The pedigree of the studied Sixteen Zea mexicana genotypes

\begin{tabular}{|c|c|}
\hline Genotype & Pedigree \\
\hline G1 & $\{\mathrm{M} \times(\mathrm{M} \times \mathrm{K}) \mathrm{F} 1\} \times \mathrm{K}$ \\
\hline $\mathrm{G} 2$ & $\{\mathrm{M} \times(\mathrm{M} \times \mathrm{G}) \mathrm{F} 1\} \times \mathrm{G}$ \\
\hline $\mathrm{G} 3$ & $\{\mathrm{M} \times(\mathrm{M} \times \mathrm{L}) \mathrm{F} 1\} \times \mathrm{L}$ \\
\hline $\mathrm{G} 4$ & $\{\mathrm{M} \times(\mathrm{M} \times \mathrm{L}) \mathrm{F} 1\} \times \mathrm{L}$ \\
\hline $\mathrm{G} 5$ & $\{\mathrm{M} \times(\mathrm{M} \times \mathrm{K}) \mathrm{F} 1\} \times \mathrm{K}$ \\
\hline G6 & $\{\mathrm{M} \times(\mathrm{M} \times \mathrm{K}) \mathrm{F} 1\} \times \mathrm{K}$ \\
\hline G7 & $\{\mathrm{M} \times(\mathrm{M} \times \mathrm{L}) \mathrm{F} 1\} \times \mathrm{L}$ \\
\hline $\mathrm{G} 8$ & $\{\mathrm{M} \times(\mathrm{M} \times \mathrm{K}) \mathrm{F} 1\} \times \mathrm{K}$ \\
\hline $\mathrm{G} 9$ & $\{\mathrm{M} \times(\mathrm{M} \times \mathrm{G}) \mathrm{F} 1\} \times \mathrm{G}$ \\
\hline G10 & $\{\mathrm{M} \times(\mathrm{M} \times \mathrm{L}) \mathrm{F} 1\} \times \mathrm{L}$ \\
\hline G11 & $\{\mathrm{M} \times(\mathrm{M} \times \mathrm{G}) \mathrm{F} 1\} \times \mathrm{G}$ \\
\hline G12 & $\{\mathrm{M} \times(\mathrm{M} \times \mathrm{G}) \mathrm{F} 1\} \times \mathrm{G}$ \\
\hline G13 & $\{\mathrm{M} \times(\mathrm{M} \times \mathrm{K}) \mathrm{F} 1\} \times \mathrm{K}$ \\
\hline G14 & $\{\mathrm{M} \times(\mathrm{M} \times \mathrm{K}) \mathrm{F} 1\} \times \mathrm{K}$ \\
\hline G15 & $\{\mathrm{M} \times(\mathrm{M} \times \mathrm{G}) \mathrm{F} 1\} \times \mathrm{G}$ \\
\hline G16 & $\{\mathrm{L} \times(\mathrm{M} \times \mathrm{K}) \mathrm{F} 1\} \times \mathrm{G}$ \\
\hline
\end{tabular}

Where: $\mathrm{L}=$ local teosinte landrace, and two imported landraces from CIMMYT; $\mathrm{K}=\mathrm{K} 67-5$ and $\mathrm{G}=\mathrm{Guatemala}$ and $\mathrm{M}=\mathrm{maize}$ (Giza 2 variety).

Genomic DNA extraction: Genomic DNA was extracted from fresh young leaves of Zea mexicana by DNeasy plant mini-kit according to the procedure of the manufacturer's instructions (Qiagen, Valencia, CA, USA). The extracted DNA quality and quantity were measured by a Thermo Scientific NanoDrop $2000^{\mathrm{TM}}$ spectrophotometer at 260 and $280 \mathrm{~nm}$.

\section{Random Amplified Polymorphic DNA (RAPD)}

RAPD-PCR was conducted using fourteen random primers provided by Eurofins, Germany. The selected primers; names and sequences are listed in Table (2). The reaction mixture contained $2 \mathrm{mM}$ of $\mathrm{MgCl}_{2} ; 1 \mathrm{x}$ GoTaq® Flexi buffer, $200 \mu \mathrm{M}$ dNTPs; $20 \mathrm{pM}$ primers; $20 \mathrm{ng}$ of the template DNA, 1U of GoTaq ${ }^{\circledR}$ Flexi DNA Polymerase and the reaction mixture was topped up with distilled $\mathrm{H}_{2} \mathrm{O}$ to $25 \mu \mathrm{l}$; (dNTPs, $\mathrm{MgCl}_{2}$, reaction buffer and Taq DNA Polymerase were supplied from Promega (Promega Corporation, USA). The amplification reaction was performed in a
Gene Amp® PCR System 9700 thermal cycler (Applied Biosystems, Foster City, California, USA). The reaction program was conducted as follows: denaturation cycle of $94{ }^{\circ} \mathrm{C}$ for $5 \mathrm{~min}$ followed by 40 cycles; $94{ }^{\circ} \mathrm{C}$ for $1 \mathrm{~min}, 36{ }^{\circ} \mathrm{C}$ for $1 \mathrm{~min}, 72{ }^{\circ} \mathrm{C}$ for 2 min, followed by an extension cycle at $72{ }^{\circ} \mathrm{C}$ for 7 min. The reaction was stored at $4{ }^{\circ} \mathrm{C}$. A volume of 15 $\mu 1$ of the PCR product was examined on $1.5 \%$ agarose gel according to Sambrook et al. (1989) using $1 \mathrm{~Kb}$ DNA molecular weight marker (Thermo, GeneRuler). DNA fragments were visualized and photographed using the Molecular Imager ( ${ }^{\circledR}$ Gel Doc ${ }^{\text {TMXR. }}$

\section{Automated Amplified Fragment Length Polymorphism (AFLP)}

Automated AFLP was carried out using the AFLP Plant Mapping Kit (PE Applied Biosystems) following the manufacturer's protocols. The EcoRI primers E-AACE and ACT were labeled with 5-NED 
and 5-FAM respectively, whereas $M s e$ I primers were unlabelled (Table 3). The five primer pairs that showed the best amplification of Zea mexicana DNA fragments were chosen for the followed selective amplification processes. The selectively amplified products were mixed with $\mathrm{Hi}$-Di formamide and GeneScan 500 ROX internal size standards (Applied Biosystems, Foster City, California, USA) before the detection with ABI PRISM 310 Genetic Analyzer (PE Applied Biosystems, Foster City, California, USA) using GS STRb POP-4 polymer as a molecular sieve.

\section{Data Analysis}

Only the sharpest RAPD bands were manually scored for further analysis. AFLP's fragment sizes and genotypes were analyzed using GeneScan and GeneMapper® Analysis Software Version 4.1 (Applied Biosystems, Foster City, California, USA). Several genetic diversity parameters were measured from RAPD and AFLP polymorphism data to compare the discriminatory power of these techniques for diversity assessment of Zea mexicana genotypes such as the number of observed alleles $(\mathrm{Na})$, the number of effective alleles $(\mathrm{Ne})$ that were calculated according to the method of Hartl and Clark (1989) and Liu and Muse (2005). Also, Shannon index (SI) was determined by the method of Shannon (1949) using POPGENE software version 1.32. Polymorphic information content (PIC) as a value of a marker for detecting polymorphism within a population was calculated using Power Marker software version 3.25 (Liu and Muse, 2005). The multiplex ratio (MR) that represents the total number of loci detected per assay and the effective multiplex ratio (EMR) were estimated according to Powell et al. (1996). The marker index (MI) was used to calculate the overall utility of a marker system according to the following equation: MI = EMR x PIC (Tonk et al., 2011). The pairwise comparisons between the tested genotypes were used to calculate the genetic similarity using the SPSS version 16.0 program according to the method described by Nei and Li (1979) and a dendrogram was constructed using the unweighted pair group method using the arithmetic average UPGMA. Power Marker version 3.0 software was used by Mantel test to determine the significance of the correlation between the two genetic distance matrices of both marker systems (Mantel, 1967).

The STRUCTURE program version 2.3.1 using the Bayesian clustering method was used to calculate the more likely number of clusters $(\mathrm{K})$ of the individuals through maximizing Hardy-Weinberg at each $\mathrm{K}$ (Pritchard et al., 2000).

\section{RESULTS AND DISCUSSION}

\section{Genetic diversity}

Molecular markers are widely used for evaluating plant germplasm and genetic diversity for assisting genetic polymorphism, parentage determination, germplasm characterization, gene mapping, genetic distance as well as in marker-assisted selection (Meng et al., 2018). In the current study, fourteen RAPD primers and five AFLP primer combinations were used to investigate the genetic polymorphism amongst sixteen Zea mexicana genotypes.

\section{RAPD Polymorphism}

The selected fourteen primers amplified a total number of 141 DNA fragments with fragment sizes ranging from 250 to $3000 \mathrm{bp}$ across the 16 studied genotypes showing an average of 10.1 bands per primer. The number of amplicons/primers ranged from 6 with primers OPB15 and OPO20 to 15 with primer OPA 20. On the other hand, the number of the polymorphic bands was 102 which represented a percentage of $72.3 \%$ with an average number of 7.3 per primer. The number of polymorphic amplicons varied from 3 with primers OPB15 and OPO20 to 12 with primer OPA20. Primer OPM18 was the most efficient one with a percentage of polymorphism of $100 \%$. On the other side, primers OPB15, OPC01, and OPO20 were only able to show 50\% polymorphism amplifying 6, 10, and 6 bands respectively. Representative RAPD profiles obtained by primers OPA20, OPB02, OPB04, and OPC01 are shown in Fig. (1). The high polymorphism recorded is reflected in germplasm management; to detect genetic 
diversity and to reveal genetic relationships. Positive and negative unique markers (PUMs and NUMs) were used in genotype identification and in generating a unique fingerprint for each genotype. Table (2) shows a total of 11 unique RAPD markers (4 PUMs and 7 NUMs) which were created by 6 primers. PUMs were generated by 4 primers which distinguish genotypes G6, G8, G14, and G16 while, NUMs successfully identified genotypes G3, G4, G5, and G12.

The present study results had a higher number of fragments (Figure 1 and Table 2) than that recorded by Sharawy et al. (2011) and Vivodík et al. (2015) on some teosi nte and maize studiesand agreed with the results of Ristic et al. (2013) who analyzed 21 genotypes with 7 primers and obtained an average of 10.8 bands per primer. Also, the present findings are in partial agreement with that of Bauer et al. (2005) who detected $78.2 \%$ polymorphic markers amongst 11 early maturing maize hybrids using 10 RAPD primers. On the other hand, Bruel et al. (2006) and Sharawy et al. (2011) obtained a higher level of polymorphism (84.44 and 99\% respectively) studying maize inbred lines using RAPD markers. The difference in the level of polymorphism obtained is mainly attributed to the degree of divergence between the different genotypes studied. However, these results confirmed that the studied Zea mexicana genotypes exhibit high genetic variations. Based on these results, the RAPD marker is considered efficient for determining the genetic variability between Zea mexicana germplasm.
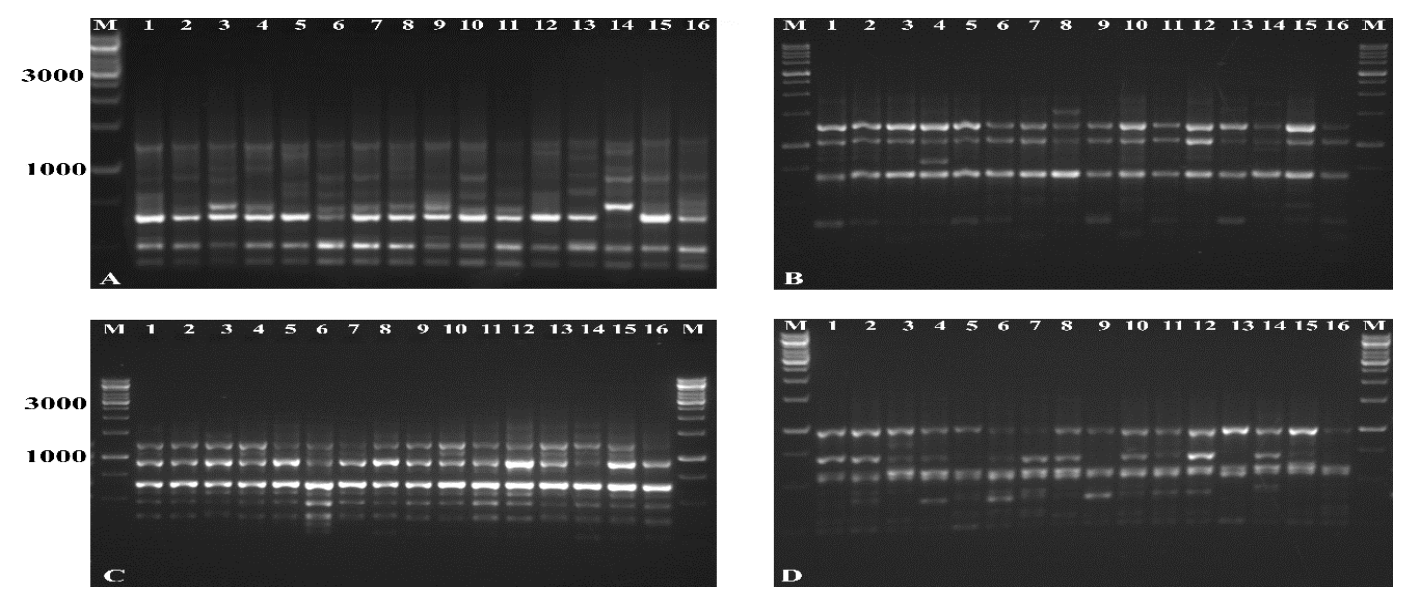

Fig. 1 Representative RAPD profiles for the sixteen Zea mexicana genotypes with primers OPA20 (A), OPB02 (B), OPB04 (C), and OPC01 (D) respectively, M is 1Kb DNA marker. Genotypes are numbered according to Table (1). 
Table 2 List of RAPD primers with their sequences, the total number of amplified bands, number of polymorphic bands, rate of polymorphism, and the number of positive and negative primers and their corresponding genotypes.

\begin{tabular}{|c|c|c|c|c|c|c|c|}
\hline \multirow[b]{2}{*}{$\begin{array}{l}\text { Primer } \\
\text { Name }\end{array}$} & \multirow[b]{2}{*}{ Primer sequence $\left(5^{\prime} \rightarrow 3^{\prime}\right)$} & \multirow[b]{2}{*}{$\begin{array}{c}\text { Total No. of } \\
\text { bands }\end{array}$} & \multirow[b]{2}{*}{$\begin{array}{c}\text { Polymorphic } \\
\text { bands (\%) }\end{array}$} & \multicolumn{2}{|r|}{ PUM } & \multicolumn{2}{|r|}{ NUM } \\
\hline & & & & $\begin{array}{c}\text { Number } \\
\text { of bands/ } \\
\text { primer }\end{array}$ & $\begin{array}{c}\text { Genotypes } \\
\text { showing positive } \\
\text { unique markers }\end{array}$ & $\begin{array}{c}\text { Number of } \\
\text { bands/ } \\
\text { primer }\end{array}$ & $\begin{array}{c}\text { Genotypes showing } \\
\text { negative unique } \\
\text { markers }\end{array}$ \\
\hline OPA 04 & AAT CGG GCT G & 8 & $6(75.0 \%)$ & - & - & 2 & G5 \\
\hline OPA 10 & GTG ATC GCA G & 14 & $10(71.4 \%)$ & 1 & G14 & 1 & G12 \\
\hline OPA 20 & GTT GCG ATC C & 15 & $12(80.0 \%)$ & - & - & - & - \\
\hline OPB 01 & GTT TCG CTC C & 12 & $10(83.3 \%)$ & - & - & 1 & G12 \\
\hline OPB 02 & TGA TCC CTG G & 10 & $7(70.0 \%)$ & 1 & G16 & - & - \\
\hline OPB 03 & CAT CCC CCT G & 11 & $9(81.8 \%)$ & 1 & G8 & 1 & G4 \\
\hline OPB 04 & GGA CTG GAG T & 11 & $6(54.5 \%)$ & 1 & G6 & - & - \\
\hline OPB 05 & TGC GCC CTT C & 7 & $4(57.1 \%)$ & - & - & - & - \\
\hline OPB 10 & CTG CTG GGA C & 9 & $7(77.8 \%)$ & - & - & 1 & G3 \\
\hline OPB 15 & GGA GGG TGT T & 6 & $3(50.0 \%)$ & - & - & - & - \\
\hline OPC 01 & TTC GAG CCA G & 10 & $5(50.0 \%)$ & - & - & - & - \\
\hline OPC 09 & CTC ACC GTC C & 11 & $9(81.8)$ & - & - & - & - \\
\hline OPM 18 & CAC CAT CCG T & 11 & $11(100)$ & - & - & - & - \\
\hline OPO 20 & ACA CAC GCT G & 6 & $3(50.0)$ & - & - & 1 & G4 \\
\hline & Total & 141 & $102(72.3 \%)$ & 4 & 4 & 7 & 4 \\
\hline
\end{tabular}

PUM: Positive Unique Markers

NUM: Negative Unique Markers

\section{AFLP Polymorphism}

Five primer combinations were selected to measure the genetic diversity of the 16 Zea mexicana genotypes. A representative AFLP electropherogram generated by genotypes G8 and G10 using primer combinations E-AAC/M-CTG is represented in Fig. (2); common peaks are highlighted in black whereas grey bars represent its corresponding alleles. An example of a polymorphic peak that is found in sample G7 and not in G6 or G11 is indicated by an arrow (Fig. 2). Each of the five AFLP combination primers used in this study successfully differentiated each of the studied 16 genotypes (Table 3). They generated a total of 276 informative fragments across the 16 Zea mexicana genotypes, with an average of 55.2 , out of them, $96.7 \%$ were polymorphic. These results are in agreement with these reported by
Legesse et al. (2006) who obtained a total of 334 AFLP bands, of which $275 \quad(81.2 \%)$ were polymorphic studying 21 CIMMYT maize inbred lines. Also, Hartings et al. (2008) analyzed the genetic diversity pattern in 54 Italian landraces using 10 primer combinations that produced 284 polymorphic AFLP bands with an average of 28 markers and the number of markers ranged from 12 to 46 . While, Neha and Nam, (2016) reported that using eight AFLP primer combinations produced a total of 232 bands studying 78 maize lines. The polymorphism percentage is similar to that of Giordani et al. (2019), who obtained $97 \%$ polymorphism using 4 primer combinations studying 145 maize accessions, which was higher than that recorded by Neha and Nam (2016) who obtained a percentage of polymorphism of $67 \%$ among maize lines. 
G7

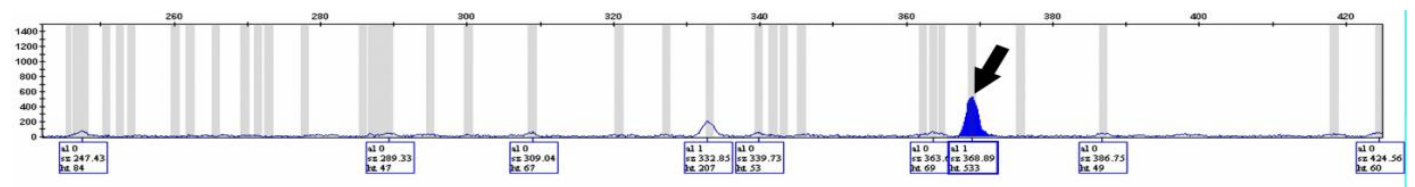

G6

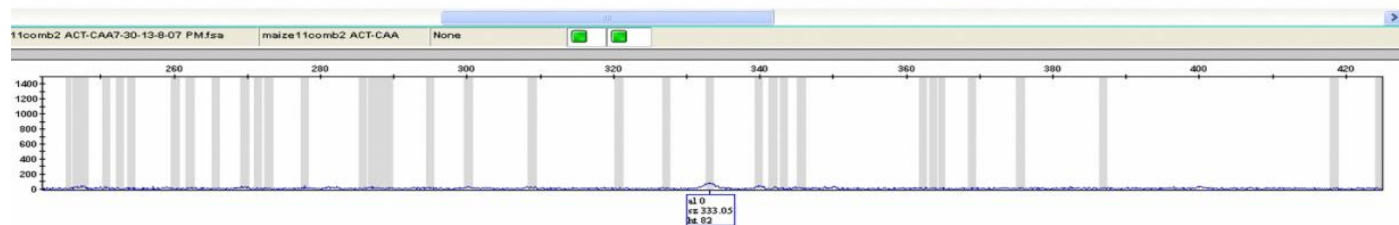

G11

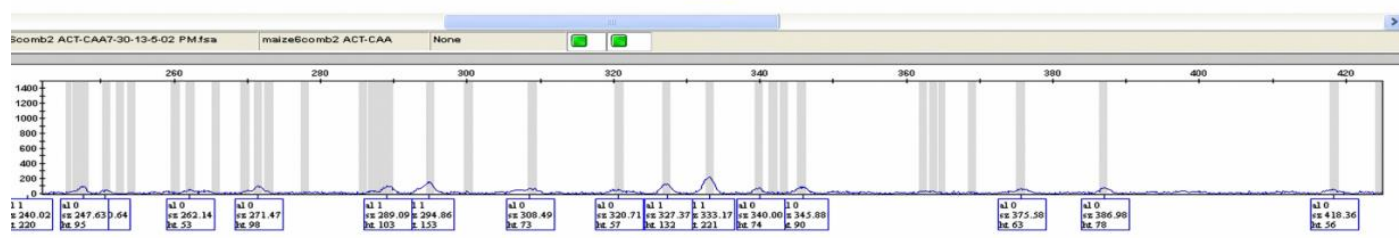

Fig. 2 Selected electropherograms of three Zea mexicana AFLP samples (G7, G6 and G11) using the primer combination E-ACT (FAM)/M-CAA. Arrow indicates an example of a polymorphic peak that is present in sample G7 and absent in G6 and G11.

These results confirm that AFLP analysis is clearly a powerful means of fingerprinting teosinte and effectively detect genetic variations in the 16 accessions studied. In addition, the highest number of unique markers (14) was recorded with combination E-ACT/M-CAA for genotypes G3, G4, and G8, while genotypes G1, G5, G7, G9, and G13 was characterized by the lowest number (6) using primer combinations E-AAC/M-CTA. Moreover, combination E-AAC/M-CTG produced the highest number of positive unique markers with the genotypes
G5, G7, G12, G13, and G16. Genotype G8 was successfully distinguished by primer combination EACT/M-CTA with a total of 10 unique markers (9 PUM and 1 NUM). While G1 was identified by 9 unique markers (6 PUM and 3 NUM). Each genotype had a unique banding profile for every AFLP primer combination. These results are in agreement with previous studies on maize using AFLP markers (Oliveira et al., 2004; Legesse et al.; 2006 Hartings et al.; 2008, Neha and Nam, 2016 and Tomkowiak, et al., 2020).

Table 3 AFLP analysis for the 16 Zea mexicana genotypes as identified by five primer combinations demonstrating the total number and the polymorphic bands, unique alleles, and the genotypes being identified by each combination.

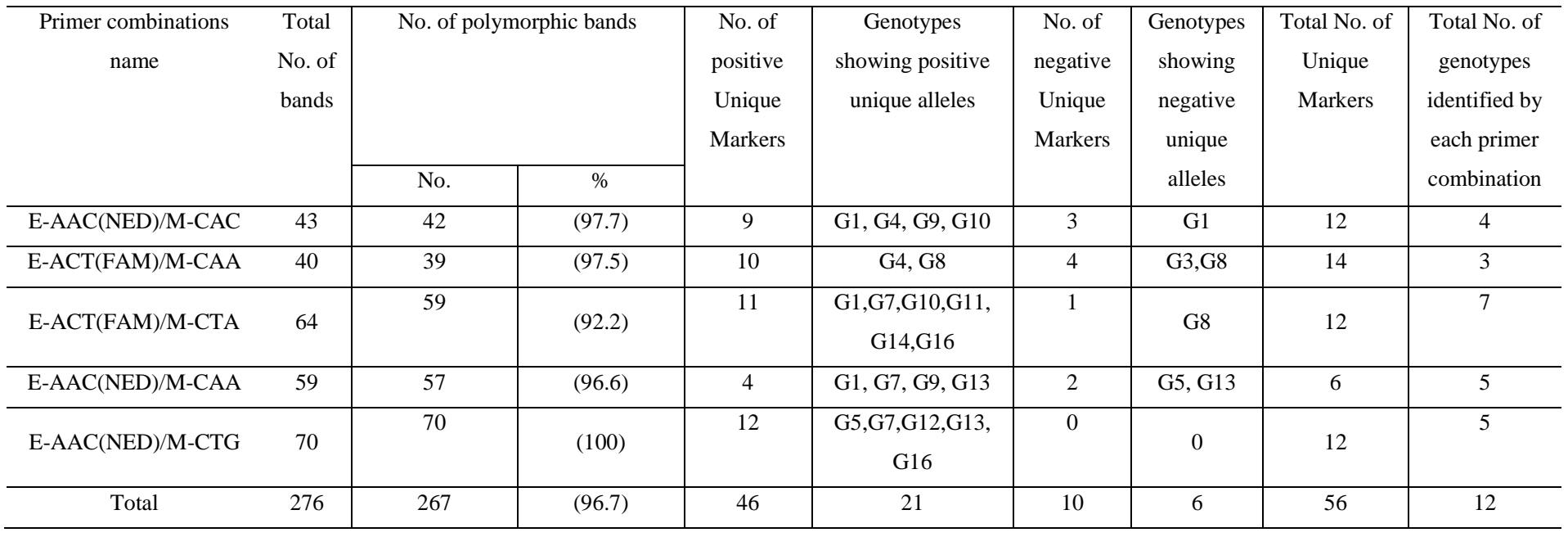




\section{Genetic relationships}

\section{Cluster analysis of RAPD data}

The genetic similarity amongst the 16 genotypes ranged from 67.0 (between G12 and G14) to 90.0 (between G7 and G10) reflecting the high genetic variability among the genotypes under study. Dendrogram based on RAPD data matrices obtained with unweighted pair group method using arithmetic means (UPGMA) grouped the 16 Zea mexicana genotypes into five major groups (Fig. 4). The first one was separated from the others containing only two genotypes (G16 and G14). The second group contained three genotypes; G1, G2, and G5. - Also, Genotypes G3 and G4 were grouped in a third group according to their genetic background. Furthermore, the fourth group contained four genotypes; G9, G12, G13, and G15. The fifth group contained the remaining genotypes; G6, G7, G8, G10, and G11. These findings are in agreement with that of Bruel et al. (2006) and Souza, et al., (2008) who constructed a dendrogram with five groups for selected maize lines based on the RAPD marker. Thus, the genetic relationships revealed by RAPD marker can be used to establish a consistent heterotic pattern between characterizing different maize lines (Carvalho et al., 2004; Rinaldi et al., 2007; Sharawy et al., 2011; Balážová, et al., 2016 and Vivodík, et al., 2017)

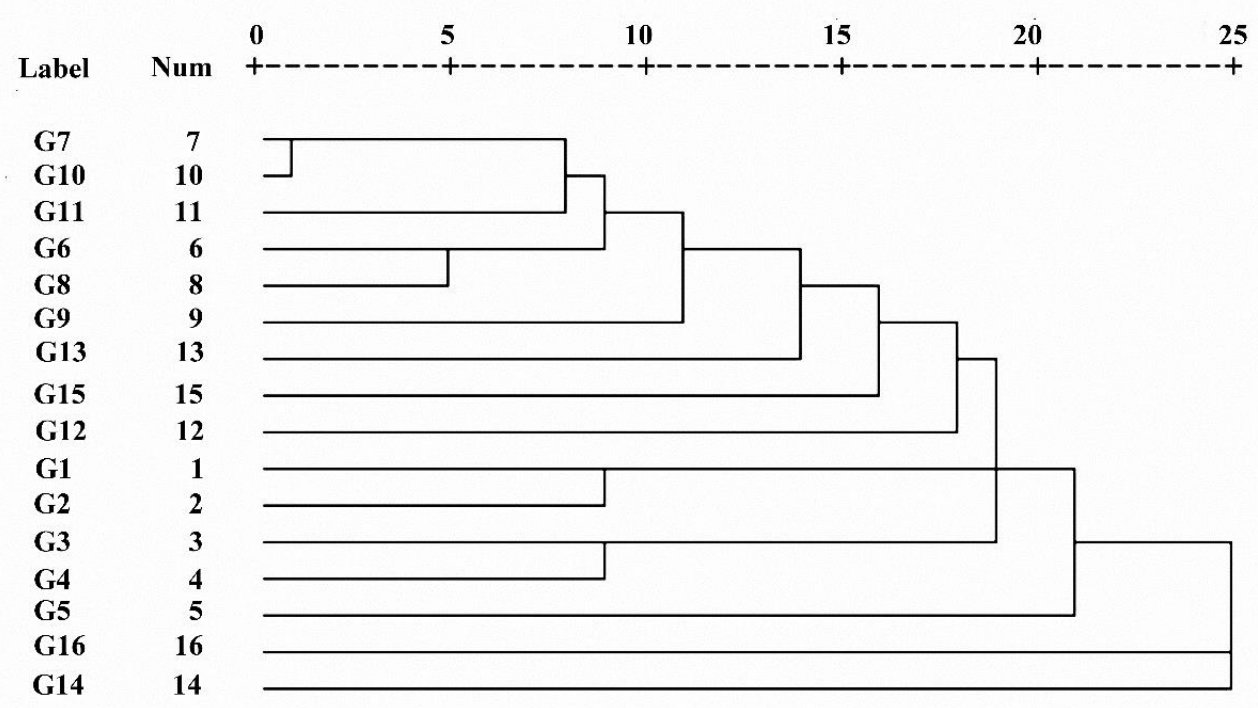

Fig. 3 Dendrogram constructed according to Nei and Li's coefficient using Unweighed Pair-group Arithmetic Average (UPGMA) and similarity matrix of the RAPD generated data for the 16 Zea mexicana genotypes.

\section{.Cluster analysis of AFLP data}

AFLP data created a genetic similarity that ranged from 15.0 between G8 and G11 to 64.0 between both G3 \& G14 and G5 \& G15 (data unpublished). AFLP dendrogram successfully separated the $16 \quad \mathrm{Zea}$ mexicana genotypes into five major groups (Fig. 5). The first group contained genotypes G7 and G16. The second group is comprised of three genotypes; G4,
G6, and G8. The third contained genotypes G1, G9, and G10. The fourth group is composed of genotypes G2, G11, G12, and G13. The remaining four genotypes were separated in the fifth group which had two closest pairs; (G3 and G14) and (G5 and G15). These findings are in agreement with that classifying maize lines based on AFLP markers data (Hartings et al., 2008; Neha and Nam, 2016; Giordani et al., 2019) 


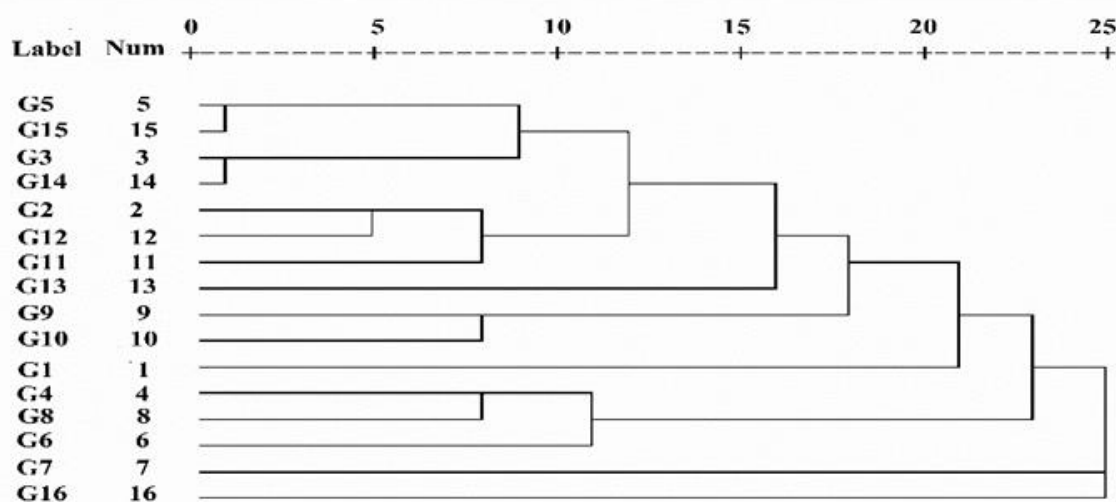

Fig. 4 Dendrogram constructed according to Nei and Li's coefficient using Unweighed Pair-group Arithmetic Average (UPGMA) and similarity matrix of the AFLP generated data for the 16 Zea mexicana genotypes

Cluster analysis of combining RAPD and AFLP data.

The estimated similarities generated from combining RAPD and AFLP data ranged from 52.0 for genotypes G8 and G11 to 73.0 for genotypes G9 and G10 (data unpublished). Combining RAPD and AFLP data (Figure 5) generated a more reliable relatedness representing the genetic relationships between the 16 Zea mexicana genotypes since combining the two molecular techniques provides extensive coverage of the Zea genome. Interestingly, the combined dendrogram showed the same topography as that of AFLP, indicating that the AFLP marker would be the best-suited molecular assay to evaluate genetic relationships with high accuracy among maize inbred lines (Garcia et al., 2004, Neha and Nam 2016 and Giordani et al., 2019).

The incongruity between our pedigree for some genotypes and the dendrogram obtained could be due to the probability of natural selection, genetic drift, environmental effects, unintentional outcrossing, and/or mutations.

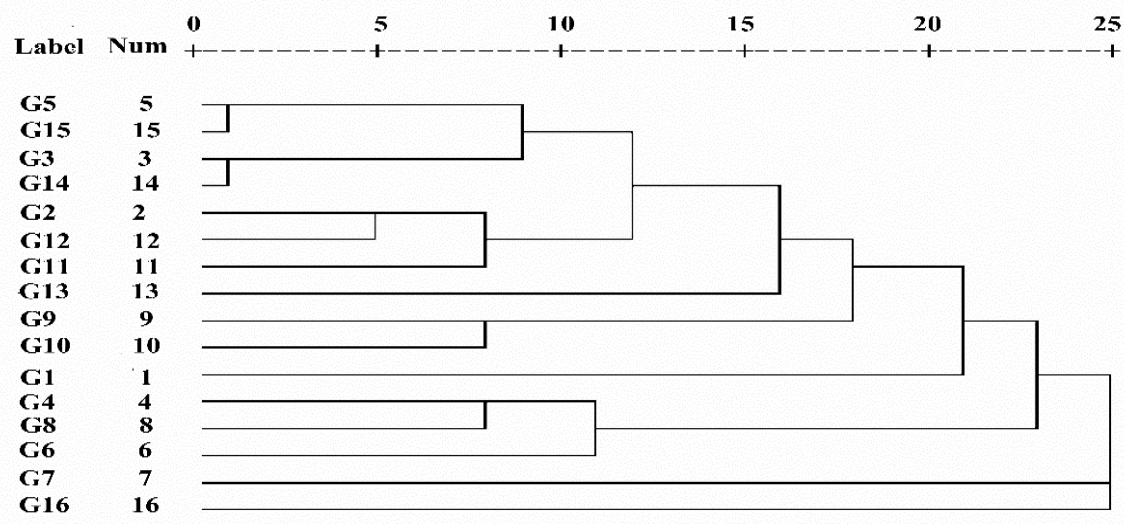

Fig. 5 Dendrogram constructed according to Nei and Li's coefficient using Unweighed Pair-group Arithmetic Average (UPGMA) and similarity matrix of the combined RAPD and AFLP generated data for the 16 Zea mexicana genotypes. 


\section{Population structure}

Population structure has been frequently applied in many genetic studies to understand the genetic diversity among maize genotypes (Belalia et al., 2019), to determine heterotic groups of maize germplasm lines (Boakyewaa Adu et al., 2019), and to control false-positive associations between marker loci and phenotypic traits (Giordani et al., 2019). The results of the population structure analysis (Fig. 7) confirmed that of the phylogenetic tree which showed that the most suitable $\Delta \mathrm{K}$ (Fig. 6) was 5. Each color in the plot represents a separate population and the length of the colored segment shows the corresponding association of each sample to their respective population. The 16 lines were identified as mixed genotypes by structure analysis because these lines were derived from local teosinte landrace; Giza 2 (maize variety) and two teosinte lines from CIMMYT
(Table 1). Interestingly, genotypes G8 and G16 were separated into two groups. The third group contained G2, G11, and G15. The fourth one included G5, G3, G12, G1, G13, and G10. The remaining genotypes; G9, G7, G14, G4, and G6 constituted the fifth one. The lines were clustered based on their ancestry and selection history. However, the clustering of some lines was not based on their shared ancestry, indicating that inbred lines extracted from the same population do not necessarily have the same selection history (Boakyewaa Adu et al., 2019 and Giordani et al., 2019).

These results are following that of Warburton et al. (2011) which reported that the structural analysis of one hundred populations from six Zea taxa; domesticated (maize) and wild (teosinte); had high concordance to each other and were capable of establishing only five clusters.

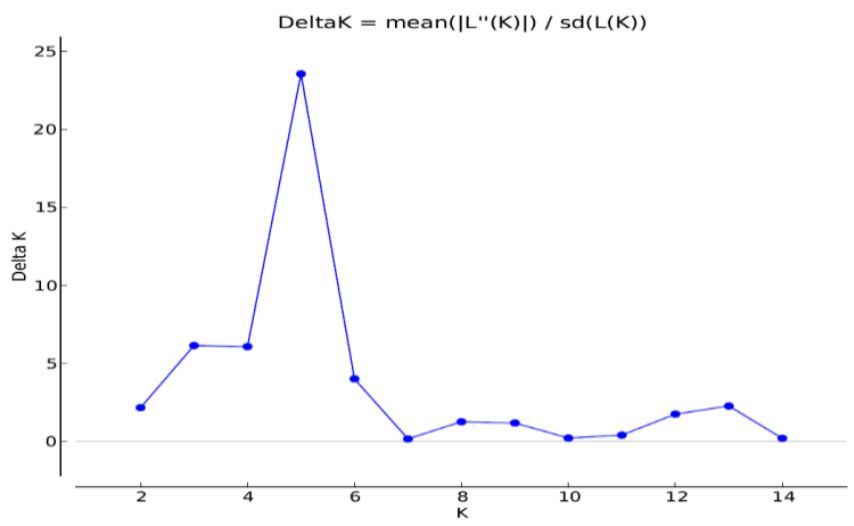

Fig.6 Bilateral chart representing the optimal number of K identified by Structure program.

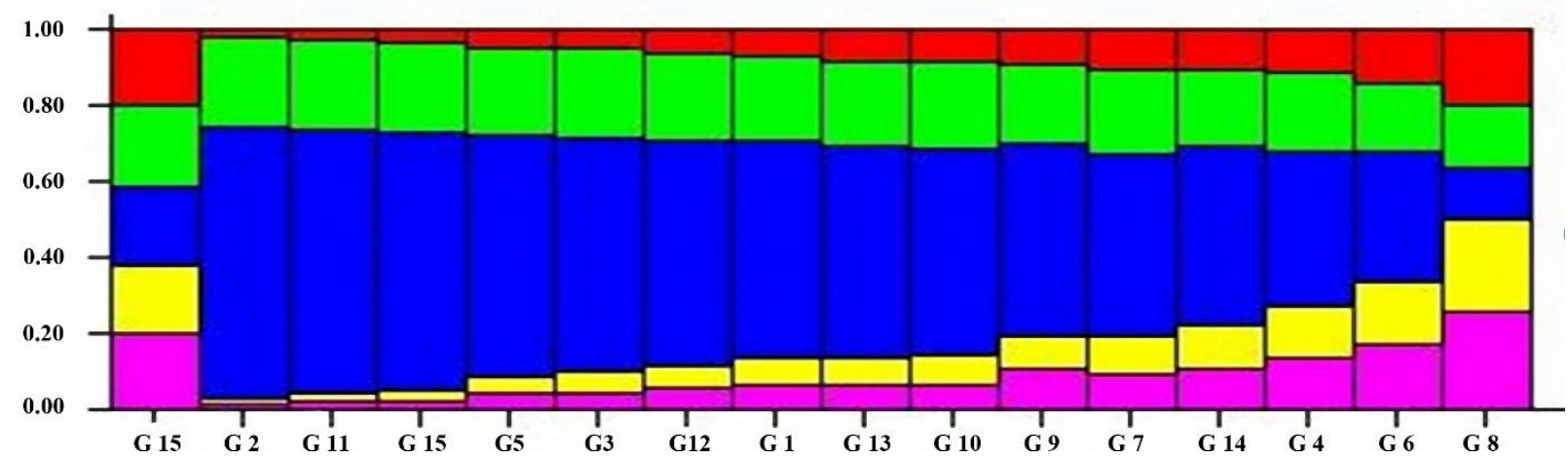

Fig.7 Population structure of the16 Zea mexicana genotypes calculated using the combined data for RAPD and AFLP using $\mathrm{K}=5$. Each color represents a separate subgroup and the length of the colored segment shows the estimated membership proportion of each sample to its corresponding group. 
Comparing the efficiency of RAPD and AFLP in analyzing Zea mexicana genome:

The efficiency of both RAPD and AFLP markers to analyze the Zea mexicana genome was compared using fourteen RAPD primers and five AFLP primer combinations respectively (Table 4). From a total of 141 RAPD bands and 276 AFLP peaks, 102 represent $72.3 \%$ and 267 represent $96.7 \%$ fragments were found to be polymorphic loci, respectively. Also, Tomkowiak, et al. (2020) compared the efficiency of AFLP, RAPD markers for determining the relationship among thirteen hybrids and nineteen inbred lines of maize. They obtained 528 AFLP markers and 234 RAPD markers using fifteen primer pairs and forty random oligonucleotide primers, respectively.

Table 4. Comparison between the efficiency of RAPD and AFLP for evaluating genetic diversity of the 16 genotypes of Zea mexicana.

\begin{tabular}{l|c|c}
\hline \multirow{2}{*}{ Parameter } & \multicolumn{2}{c}{ Marker } \\
\cline { 2 - 3 } & RAPD & AFLP \\
\hline Number of assays screened & 14 primers & 5 primer combinations \\
\hline Total number of bands & 141 & 55.2 \\
\hline Multiplex ratio (MR) & 10.1 & 267 \\
\hline Number of polymorphic bands & 102 & $96.7 \%$ \\
\hline Polymorphism \% per assay & $72.3 \%$ & $2.00 \pm 0.04$ \\
\hline Observed number of alleles (Na) & $1.67 \pm 0.47$ & $1.30 \pm 0.30$ \\
\hline Effective number of alleles (Ne) & $1.43 \pm 0.39$ & 53.4 \\
\hline Effective Multiplex ratio (EMR) & 7.3 & 0.21 \\
\hline Polymorphic information content (PIC) & 0.15 & $0.33 \pm 0.19$ \\
\hline Shannon index (I) & $0.36 \pm 0.29$ & 11.21 \\
\hline Marker index (MI) & 1.10 & \multicolumn{1}{c}{ (E) } \\
\hline
\end{tabular}

PIC is considered as the better parameter for measuring genetic diversity than the number of alleles, taking into account the relative frequencies of each allele Aci et al. BMC Genetics (2018)

Moreover, Na, EMR, and PIC indices showed higher values for RAPD $(1.67 \pm 0.47,7.3$, and 0.15$)$ than for $\operatorname{AFLP}(2.00 \pm 0.04,53.4$, and 0.21). On the other hand, the Shannon index (I) was fairly lower for RAPD $(0.36 \pm 0.29)$ comparing to that of AFLP $(0.33 \pm 0.19)$. While the effective number of alleles $(\mathrm{Ne})$ of RAPD was slightly higher $(1.43 \pm 0.39)$ than that of AFLP $(1.30 \pm 0.30)$. Moreover, the marker index (MI) of RAPD (1.1) was significantly lower compared to that of AFLP (11.21). These values agree with that obtained by Roy et al. (2015) and Neha and Nam (2016). Moreover, the level of polymorphism observed in this study agrees with that of Lubberstedt et al. (2000) and Oliveira et al. (2004). The informativeness of the primer combinations can be ascertained by the PIC and MI values because the values indicate the discriminatory power of a marker system by taking into consideration the number of alleles at a locus and the relative frequencies of these alleles (Powell et al., 1996). In this respect, we obtained relatively higher values of PIC (0.24) and MI (19.4) underlining the discriminatory power of the AFLP marker (Lubberstedt et al., 2000 Oliveira et al., 2004) and indicating the relatively high level of variability existing among the inbred lines under investigation. Moreover, Bahulikar et al. (2004) reported that AFLP showed a higher percentage of polymorphic loci than the ISSR marker. In contrast, 
Biswas et al. (2011) obtained higher levels of polymorphism with ISSR than with AFLP, while Krichen et al. (2010) stated equal results for molecular markers. However, our results indicate that AFLP is the best-suited molecular assay for fingerprinting and assessing genetic relationships among tropical maize inbred lines with high accuracy. The correlation degree between similarity matrices obtained by both RAPD and AFLP indicated non-significant correlation values estimated through the "Manteltest" indicating that genetic diversity studies are very essential in the selection of individual genotypes among closely related groups.

\section{CONCLUSION}

Supporting the superiority of molecular marker data to define groups of populations with similar origins. The findings of the present study revealed that the two dominant markers (RAPD and AFLP) were successfully effective in measuring the genetic variation in the 16 Zea mexicana genotypes. Moreover, AFLPs have the advantage of having a higher marker index compared to that of RAPD, as well as its high reproducibility. The genetic diversity detected offers promising data for the development of new cultivars and the use of more than one variable marker enables a better exploring of the Zea genetic diversity providing a better tool for Zea breeding programs, registration, and varieties protection. Finally, the data obtained can be used for varietal survey and construction of germplasm collection and provides also additional information that could form the basis for the rational design of breeding programs.

\section{Supporting}

Competing Interest: Authors have declared that no competing interest exists.

\section{ACKNOWLEDGMENT}

The authors would like to thank the Agricultural Genetic Engineering Research Insititute (AGERI), Giza, Egypt, and the college of pharmacy at Prince Sattam Bin Abdulaziz University, Kingdom of Saudi Arabia for providing the necessary facilities to carry out this research work.

\section{ABBREVIATIONS}

(PIC) Polymorphism information content; (Na) observed alleles; (EMR) effective multiplex ratio; (RAPD) randomly amplified polymorphic DNA; (AFLP) Amplified fragment length polymorphism.

\section{REFERENCES}

Aci, M.M., Lupini, A., Mauceri, A., Abdelkader Morsli, L.K. and Sunseri, F. (2018). Genetic variation and structure of maize populations from Saoura and Gourara oasis in Algerian Sahara. BMC Genet 19, 51. https://doi.org/10.1186/s12863-018-0655-2

Belalia, N., Lupini, A., Djemel, A., Morsli, A., Mauceri A., Lotti, C., Khelifi-Slaoui M., Khelifi, L. and Sunseri, F. (2019). Analysis of genetic diversity and population structure in Saharan maize (Zea mays L.) populations using phenotypic traits and SSR markers. Genet. Res. and Crop Evol. 66, 243-257.

Bahulikar, R.A., Stanculescu, D., Preston, C.A., and Baldwin, I.T. (2004). ISSR and AFLP analysis of the temporal and spatial population structure of the postfire annual, Nicotiana attenuata, in SW Utah. BMC Ecol. 4:12. PMID: 15350209.

Balážová, Ž., Vivodík, M. and Gálová, Z. (2016). Assessment of RAPD polymorphism in ricin genotypes. J. Microbiol. Biotech. and Food Sci. 5 (4) 386-388.

https://doi.org/10.15414/ jmbfs.2016.5.4.386-388.

Barcaccia G., Margherita L. and Martino C. (2016). DNA Barcoding as a Molecular Tool to Track Down Mislabeling and Food Piracy. Div. 8:1-16. https://doi.org/10.3390/d8010002.

Bauer ,I., Drinić, S. M., Filipović, M. and Konstantinov, K. (2005). Genetic Characterization of Early Maturing Maize Hybrids (Zea mays L.) Obtained by Protein And RAPD Markers. Genet. 37 ( 3): 235-243.

Biswas, M.K., Chai, L., Amar, M.H., Zhang, X. and Deng, X.X. (2011). Comparative analysis of genetic diversity in Citrus germplasm collection using AFLP, SSAP, SAMPL and SSR markers. Sci. Hortic. 129: 798-803.

Boakyewaa Adu. G., Badu-Apraku, B., Akromah, R., Garcia-Oliveira, A.L., Awuku, F.J. and Gedil, M. (2019). Genetic diversity and population structure of 
early-maturing tropical maize inbred lines using SNP markers. PLoS ONE 14 (4): e0214810. https://doi.org/10.1371/ journal.pone.0214810.

Carvalho, L.C., Luíis, G., Cristina, O., José, C. G. and Sara, A. (2004). RAPD Assessment for Identification of Clonal Identity and Genetic Stability of in vitro Propagated Chestnut Hybrids. Plant Cell, Tissue and Organ Culture 77: 23-27. https://doi.org/10.1023/ B: TICU.0000016482.54896.54.

Chavez, N.B., Flores, J.J., Martin, J., et al. (2012). Maize x Teosinte Hybrid Cobs Do Not Prevent Crop Gene Introgression. Econ. Bot. $66 \quad$ (2):132-137. doi:10.1007/s12231-012-9195-2.

Cristina, B.D., Carpentieri-Pípolo, V., Gerage, A.C., Júnior, N., da Silva F.; Prete C.E. C.; Ruas, C. de F.; Ruas, P.M.; Hülse de Souza, S.G. and Garbuglio, D.D. (2006). Genetic distance estimated by RAPD markers and its relationship with hybrid performance in maize 41 (10): 1491-1498. http://dx.doi.org/10.1590/S0100204X2006001000006

Franklin, R.B., Taylor, D.R., Mills, A.L., (1999). Characterization of microbial communities using randomly amplified polymorphic DNA (RAPD). J. Microbiol. Methods 35: 225-235.

Fukunaga K, Hill J, Vigouroux Y, et al (2005). Genetic diversity and population structure of teosinte. Genetics 169 (4): 2241-2254. doi:10.1534/genetics.104.031393

Garcia A.A.F., Benchimol L.L., Barbosa A.M.M., Geraldi I.O., Júnior C.L.S. and De Souza A.P. (2004). Comparison of RAPD, RFLP, AFLP and SSR markers for diversity studies in tropical maize inbred lines. Genet. Mol. Biol. 27:579-588.

Giordani, W. , Carlos, A.S. , Paulo, M.R., Claudete de Fátima, R., Rodrigo C. , Marlon, C., Inês Cristina de Batista, F., Leandro, S.A.G. (2019). Genetic diversity, population structure and AFLP markers associated with maize reaction to southern rust. Bragantia, Campinas, 78 (2): 183-196.
Hartings, H., Berardo, N., Mazzinelli, G.F. Valoti,P.,Verderio,A. and Motto, A. (2008). Assessment of genetic diversity and relationships among maize (Zea mays L.) Italian landraces by morphological traits and AFLP profiling. Theor. Appl. Genet. 117: 831. https://doi.org/10.1007/ s00122-008-0823-2

Hartl, D. L., Clark, A. G. (1989). Principles of population genetics, Second ed. Sunderland, MA: Sinauer Associates.

Hassan, H.H.M., Sayed, M.R.I. and Mousa, W.M.E. (2017). Effect of Intercropping Patterns on Forage Yield and Land Use Efficiency of Some Summer Fodder Crops. Zagazig J. Agric. Res. 44 (6A): $2007-$ 2020.

Krichen, L., Bourguiba, H., Audergon, J.M. and TrifiFarah N. (2010). Comparative analysis of genetic diversity in Tunisian apricot germplasm using AFLP and SSR markers. Sci. Hortic. 127: 54-63.

Kyu, J., Tak, K.H. and Ju, K.L. (2018). Genetic Diversity and Association Analyses of Canadian Maize Inbred Lines with Agronomic Traits and Simple Sequence Repeat Markers. Plant Breed. Biotech. 6 (2): 159-169.

Legesse, B.W., Myburg, A.A., Pixley, K.V. and Botha, A.M. (2006). Genetic diversity analysis of CIMMYTmid-altitude maize inbred lines using AFLP markers. S. Afr. J. of Plant and Soil, 23(1): 4953.

https://doi.org/10.1080/02571862.2006.10634729

Liu, K. and Muse, S.V. (2005). Power Marker: Integrated Analysis Environment for Genetic Marker Data. Bioinf. 21: 2128-2129. https://doi.org/10.1093/bioinformatics/bti282.

Lubberstedt, T., Melchinger, A.E., DU, C., Vuylsteke, L.M. and Kuiper, M. (2000). Relationships among early European maize inbreds: IV. Genetic diversity revealed with AFLP markers and comparison with RFLP, RAPD, and pedigree data. Crop Sci. 40, 783 791. 
Luis, F.C.S., Rubén, H.A., Esaú, S.R., Luis, L., René Garruña, J.O. and Jaime, M. (2017). Characterization of the genetic structure and diversity of maize (Zea mays L) landrace populations from Mexico. Maydica. 62.

Mantel, N. (1967). The detection of disease clustering and a generalized regression approach. Cancer Research. 27: 209-220.

Meng, Z., Song, F., and Liu,T. (2018). Genetic diversity and genetic structure analysis of maize (Zea mays) landraces in Tibet. Int. J. of Agri. and Biol. 20: 791798.

Mohamed, A.A., EL-Far, M.M.M. and Saad, M.E. (2016). Fingerprinting of Sweetpotato Germplasm Using AFLP, RAPD and SAMPL Analysis. Egypt. J. Genet. Cytol. 45:383-401.

Molin, D., Coelho, C.J., Máximo, D.S., Ferreira, F.S., Gardingo J.R. and Matiello, R.R. (2013). Genetic diversity in the germplasm of tropical maize landraces determined using molecular markers. Genet. and Mol. Res. 12: 99-114. DOI: 10.17957/JJAB/15.0565.

Neha, S.R. and Nam-Soo, K. (2016). Genetic diversity analysis of maize lines using AFLP and TE-based molecular marker systems. Gen. and Genom. 38(10): 1005-1012. DOI 10.1007/s13258-016-0461-z.

Nei, M. and Li, W. (1979). Mathematical model for studying genetic variance in terms of restriction endonucleases. Proceeding of the National Academy of Science. U S A. 76: 5269-5273. https://doi.org/10.1073/pnas.76.10.5269.

Oliveira, K.M., Laborda,P.R., Garcia,A.A.F., Zagatto Paterniani, M.E.A. and Souza,A.P.)2004). Evaluating genetic relationships between tropical maize inbred lines by means of AFLP profiling. Hereditas. 140: 24 33. https://doi.org/10.1111/j.1601-5223.2004.01702.x.

Petr, S., Matthew, N., Nelson, J., Berger, D. and von Wettberg, B. (2018). The Impact of Genetic Changes during Crop Domestication. Agron. 8: 119. http://dx.doi.org/10.3390/ agronomy8070119.

Powell, W., Morgante, M., Andre, C., Hanafey M., Vogel, J., Tingey, S., and Rafalski, A. (1996). The comparison of RFLP, RAPD, AFLP and SSR (microsatellite) markers for germplasm analysis. Mol. Breed. 2: 225-238.

Prasanna, B.M. (2012). Diversity in global maize germplasm: Characterization and utilization. J Biosci. 37, 843-855. https://doi.org/10.1007/s12038012-9227-1.

Pritchard, J. K., Stephens, M., and Donnelly, P. (2000). Inference of population structure using multilocus genotype data. Genet. 155: 945-959.

Radwan, M. S., Taha, R. S., Rammah, A. M. and Ibrahim, H. L. (2000). A study of variation and combining ability among exotic and local teosinte accessions. Egypt. J. Plant Breed. 4: 189-200.

Ramakrishnan, M., Antony,Y., Ceasar, S., Duraipandiyan,V., Al-Dhabi, N.A. and Ignacimuthu, S. (2016). Assessment of genetic diversity, population structure and relationships in Indian and non-Indian genotypes of finger millet (Eleusine coracana $\mathrm{L}$. Gaertn) using genomic SSR markers. Sprin. Plus 5(120): 1-11. https://doi.org/10.1186/s40064-015$1626-\mathrm{y}$.

Rinaldi, D.A., Pípolo, V.C., Gerage, A.C., Ruas, C.F., Fonseca Júnior, D., Souza, A., Souza, S.G.H., and Garbuglio, D. (2007). Correlação entre heterose e divergência genética estimadas por cruzamentos dialélicos e marcadores moleculares RAPD em populações de milho-pipoca Correlation between heterosis and genetic divergence estimated of diallel crosses and RAPD molecular markers in populations of popcorn). Bragantia, Campinas, Brazil. 66 :183192.

Ristic D., Vojka, B., Violeta, A., Snežana M.D., Dragana, I. (2013). Genetic diversity in maize dent landraces assessed by morphological and molecular markers. 
Genet. 45: 811-824. DOI: 10.2298/ GENSR1303811R.

Roy N., Choi J.Y., Lim M.J., Lee S.I., Choi H.J.and Kim N.S. (2015). Genetic and epigenetic diversity among dent, waxy, and sweet corns. Gen. Genom. 37:865874.

Sambrook J., Fritsch E.F., and Maniatis,T. (1989). Molecular cloning. A laboratory manual. New York, USA: Cold Spring Harbor Laboratory Press.1-1652.

Sánchez González JJ, Ruiz Corral JA, García GM, Ramırez O. G., Larios, L. Dela C., Brendan, H. J., Miranda, M. R., and Emmanuel, G. R. G. (2018). Ecogeography of teosinte. PLoS One. 13(2)1-24. doi:10.1371/journal.pone.0192676.

Sánchez, G J. J., Cruz, L. L., De La Vidal, M. V. A., Ron, P. J., Taba, S., Santacruz, R.F., S. Sood, Holland, J.B., Ruíz, C.J.A., Carvajal S., Aragón, C. F., Chávez, T.V.H., Morales, R.M.M., and Barba, G. á lez R. (2011). Three new teosintes (Zea Spp., Poaceae) from Mexico. Am. J. of Bot. 98 (9): 1537-1548. https://doi.org/10.3732/ajb.1100193.

Sakr, H. O. (2017). Gene Action for Several Important Traits in Some Promising Maize - Teosinte Hybrids Using Generation Mean Analysis. J. Agric. Chem. and Biotechn., Mansoura Univ. 8(1): 15-20.

Shannon, C.E. (1949). Communication theory of secrecy systems. Bell Sys. Tech. J. 28: 656-715. https://doi.org/10.1002/j.1538-7305. 1949.tb00928.x.

Souza S. G. H. de, Carpentieri-Pípolo V., Ruas C. de F., Carvalho V. de P., Ruas P.M. and Gerage, A.C. (2008). Comparative analysis of genetic diversity among the maize inbred lines (Zea mays L.) obtained by RAPD and SSR markers, Braz. arch. biol. technol., 51: (1) 183-192.

Suten, D., Bacila, L., Has, V., Has, L., and Micclaus, M. (2013). Romanian Maize (Zea mays) Inbred Lines as a Source of Genetic Diversity in SE Europe and Their Potential in Future Breeding Efforts. PLOS ONE. 8: e85501. https://doi.org/10.1371/annotation/85f0b730b723-4d59-a653-d48b974c366c.

Tomkowiak A., Bocianowski J., Kwiatek M., Sław P.and Kowalczewski Ł. (2020). Dependence of the heterosis effect on genetic distance, determined using various molecular markers. Open Life Sci. 15: 1-11.

Tanvir, H., Dar, R. and Shusheel,V. (2018). Comparative Germplasm Characterization of Maize (Zea mays L.) in Rajouri Region of Pir Panjal Himalaya J, \& K (India), based on Morphological and ISSR Markers. J. of Crop Sci. and Biotech. 21 (1): $43-$ 55. DOI: 10.1007/s12892-017-0128-0.

Tonk, F.A., Gıachıno, R. R. A, Sönmez, Ç., Yüce, S., Bayram, E., Telci, İ. and Furan, M. (2011). Characterization of various Hypericum perforatum clones by hypericin and RAPD analyses. Int. J. of Agr. and Biol. 13: 31-37.

Varsha, G., Shahi,J.P., Srivastava, K. and Prudhvi, R.V. (2018). Assessment of Genetic Diversity and Variability of Maize (Zea mays L.) Inbreds. Int. J. of Curr. Microb. and Appl. Sci. 7 (8): 1377-1383.

Violeta A., Ana N., Dragan, K., Snezana, M., Natalija, K., Vojka, B.M.S., Mirjana, J., Sonja, I., Dane, B. (2018). Conserving maize in gene banks: Changes in genetic diversity revealed by morphological and SSR markers. Chilean J. of Agr. Res. 78(1). DOI: 10.4067/S0718-58392018000100030.

Vivodík M., Balážová Ž., Gálová Z. and Petrovičová L. (2017). Genetic diversity analysis of maize (Zea mays L.) using SCoT markers. J. of microb. Biotech. and food sci. 6(5):1170-1173.

Vivodík, M., Balážová, Ž., Gálová, Z., and Hlozakova, T. K. (2015). Genetic diversity of maize (Zea mays) accessions revealed by random amplified polymorphic DNA markers. Hort. Biotech. Res. 1: 30-34.

Sharawy, W.M., Ibrahim H.I.M. and EL-Fiky, Z.A. (2011). Phylogenetic Relationships among Teosinte, Maize 
and its Hybrids. Egy. J. of Gen. and Cyt. 40:(1) 129144.

Warburton, M.L., Wilkes, G., Taba, S. et al. Gene flow among different teosinte taxa and into the domesticated maize gene pool. Genet. Resour. Crop. Evol. 58: 1243-1261 (2011). 